\title{
Author Correction: Heat flows in rock cracks naturally optimize salt compositions for ribozymes
}

T. Matreux (D), K. Le Vay (D), A. Schmid, P. Aikkila DD, L. Belohlavek, A. Z. Çalıșkanoğlu, E. Salibi, A. Kühnlein, C. Springsklee, B. Scheu, D. B. Dingwell DD, D. Braun D, H. Mutschler (D) and C. B. Mast (iD

Correction to: Nature Chemistry https://doi.org/10.1038/s41557-021-00772-5; published online 26 August 2021

In the version of this Article initially published, the second author's name "K. Le Vay" was incorrectly spelt "K. LeVay." This error has now been corrected in the author list, correspondence line, Author Contributions and Acknowledgements sections of the paper.

These changes have been made to the print and online versions of the Article.

Published online: 9 September 2021

https://doi.org/10.1038/s41557-021-00808-w

(๑) The Author(s), under exclusive licence to Springer Nature Limited 2021

\section{Author Correction: Cyclic polyacetylene}

Zhihui Miao, Stella A. Gonsales (1), Christian Ehm (1), Frederic Mentink-Vigier (1), Clifford R. Bowers, Brent S. Sumerlin (1) and Adam S. Veige (1)

Correction to: Nature Chemistry https://doi.org/10.1038/s41557-021-00713-2, published online 3 June 2021

In the version of this Article initially published, a typo appeared in reference to Sondheimer in the second sentence of the third paragraph, and in Fig. 1a panel and caption. Additionally, the following text was missing from the end of the Acknowledgements section: "The MAS-DNP instrument at NHMFL is supported by the NIH P41 GM122698 and NIH S10 OD018519 grants."

These changes have been made to the online version of this Article.

Published online: 14 September 2021

https://doi.org/10.1038/s41557-021-00809-9

(c) The Author(s), under exclusive licence to Springer Nature Limited 2021

\section{Publisher Correction: A proteome-wide atlas of lysine-reactive chemistry}

Mikail E. Abbasov, Madeline E. Kavanagh (1), Taka-Aki Ichu, Michael R. Lazear (1), Yongfeng Tao, Vincent M. Crowley, Christopher W. am Ende, Stephan M. Hacker (1D, Jordan Ho, Melissa M. Dix, Radu Suciu, Matthew M. Hayward, Laura L. Kiessling and Benjamin F. Cravatt (B)

Correction to: Nature Chemistry https://doi.org/10.1038/s41557-021-00765-4, published online 9 September 2021.

The original version of this Article was published with an early version of the Data availability statement. The statement has now been updated to include the sentence "All raw proteomics data have been uploaded to the PRIDE repository with PRIDE ID PXD025829."

The change has been made to the online version of the Article.

Published online: 29 September 2021

https://doi.org/10.1038/s41557-021-00823-x

(c) The Author(s), under exclusive licence to Springer Nature Limited 2021 